\title{
The indigenous methodology as a method for studying social processes in the arctic
}

\author{
Ulyana Vinokurova ${ }^{1,2,3, *}$, Akulina Mestnikova ${ }^{1}$, and Galina Alekseeva ${ }^{1}$ \\ ${ }^{1}$ Churapcha State Institute of Physical Education and Sports, 2a, st. Sportivnaya, Churapcha, 678671, Russian Federation, \\ ${ }^{2}$ Arctic State Institute of Culture and Arts, 4, st. Ordzhonikidze, Yakutsk, 677027, Russian Federation, \\ ${ }^{3}$ North-Eastern Federal University named by M.K. Ammosov, 58, st. Belinsky, Yakutsk, 677000, Russian Federation
}

\begin{abstract}
In 2020, under the guidance of Doctor of Sociological Sciences Ulyana Vinokurova, the textbook "Social Processes in the Arctic" was published. It presents results of the studies on the sociology of the Arctic as a circumpolar macro-region conducted by sociologists of Yakutia. The textbook is the beginning of the series "Sociology in the Arctic" and the scientific and educational project of Arctic research, which forms the basis of Arctic education. This article presents the summary 4 modules containing the results of scientific research introduced into the educational disciplines of the social and humanitarian cycle. The first module presents the theoretical part; the second module is "The Arctic as a social phenomenon"; module 3 is "Social dynamics in the Arctic"; module 4 is "Social differentiation". Special attention is paid to the social processes in the Arctic investigated with the indigenous methodology, factors of stability and risks of geo-eco-socio-systems of the indigenous peoples of the Arctic. This manual creates an opportunity for an independent search for information, trends in socio-humanitarian knowledge in Arctic studies.
\end{abstract}

\section{Introduction}

The study of specific social processes in the Arctic through the Indigenous Methodology, identification of resilience and risk factors for geo-eco-socio-systems of indigenous peoples of the Arctic are aimed at enriching science through the interpretations of prospects and interests of indigenous peoples made by indigenous scholars in order to provide the best understanding of indigenous peoples as subjects of history. There is an indigenization of scientific knowledge both in the form of academic research and results of civil science.

Arctic education is an innovative model of continuous general and professional practice-oriented education aimed at training specialists with an Arctic identity, possessing complex competencies to improve the quality of life in the Arctic.

\section{Materials and methods}

The northern expanses became the Arctic after the collapse of the Soviet Union. Russia has lost its southern underside and has become a more northerly cold country than the Soviet Union. The expanses of the Arctic Ocean opened up thanks to the collapse of the "Iron Curtain". In Soviet times, we were not interested in other Arctic Ocean shores. Moreover, many Russians did not even know that it has an international name - the Arctic Ocean.

It was only in the 1990s that Russia began to recognize itself as a maritime power due to the growing importance of the Arctic Ocean, whose shores were perceived as alien at the beginning of perestroika. At that time the reformers mercilessly dealt with the naval, military, fishing, transport bases on Russian waters and the coastal land of the ocean. The population of the Far North was declared surplus. The collapse of the unified national economic complex in industry led to the liquidation of workers ' settlements and industrial sites, and the indigenous population was left without state protectionism.

Currently, about 2.4 million people live in the Arctic and subarctic zones of Russia. Arctic residents ask themselves "Do we need us?", "Do the Arctic need us?" Also, the question remains relevant: "To settle in the Arctic or to master it by shift methods?" This question shows that the social problems of the indigenous population of the Arctic, who inhabited the Arctic territories tens of thousands of years ago, are still not taken into account.

Indigenous peoples in a situation of scientific and educational inequality, lacking scientific competence may lose the ability to act as an independent subject of social progress in modern human history. Adherents of the Indigenous Methodology strive to develop strategies for social transformation for the benefit of these communities, to involve people who accept ideas and values of indigenous peoples and do not have the opportunity to enjoy the right of self-government and self-determination, to influence social and educational policies aimed to protect intellectual property and rights established by the UN Declaration of the Rights of the

Corresponding author: uottaah1707@gmail.com 
World's Indigenous Peoples (2007). New paradigms are required to find answers to modern challenges:

- the Earth's climate, ecological transformation: a response to global warming;

- the Limitrophe: a response to civilizational shifts;

- openness: a response to the growing multi-ethnicity of the social environment and active migration, global information society;

- body's reserves: response to changes in the pace, rhythm and content of adaptation to the new;

- the mentality paradigm: a response to the change in the materialistic worldview, the sixth technological order;

- destiny for indigenous peoples: a response to the influence of the overwhelming majority of communities, among which it is necessary to preserve own identity and integrity;

- power: a response to changing political systems.

The Indigenous Methodology expresses a general direction of development of this type of scientific rationality, which recognizes the subjectivity of the scientist, his social experience, social status, responsibility for the fate of the native people under study. The scientific systematization of knowledge does not go from the general to the particular. It goes from His own to the Other as the most important principle of selection and building of knowledge about the world. In this focus, the path of scientific knowledge is a process of understanding culture, entering it, discovering and protecting it.

Methodological peculiarity in the epistemology of indigenous scientists: Indigenous Knowledge for indigenous scientists does not have the prefix "traditional" knowledge, since it is presented in the temporal continuity of the past-present-future. Attention is paid to the education of the younger generation, the Indigenous Methodology is used as an educational paradigm [1].

\section{Results}

In 2020, under the guidance of Doctor of Sociological Sciences Ulyana Vinokurova, the textbook "Social Processes in the Arctic" was published. It presents results of the studies on the sociology of the Arctic as a circumpolar macro-region conducted by sociologists of Yakutia. This manual creates an opportunity for an independent search for information, trends in sociohumanitarian knowledge in Arctic studies. The textbook is the beginning of the series "Sociology in the Arctic" and the scientific and educational project of Arctic research, which forms the basis of Arctic education. The first issue consists of four modules containing the results of scientific research introduced into the educational disciplines of the social and humanitarian cycle.

\section{Discussion}

The first module «Theoretical frameworks» presents the theoretical part and consists of sections devoted to social institutions as regulators of the social structure
(Vasiliy E. Okhlopkov, Doctor of Sociological Sciences); describes different approaches and identifies possibilities of using the Indigenous Methodology in the study of modern society (Uliana A. Vinokurova, Doctor of Sociological Sciences); describes methodological aspects of sociological research of historical memory and cultural trauma (Akulina E. Mestnikova, Candidate of Sociological Sciences) and social policies in the Arctic (on the example of activities of the First President of the Republic of Sakha (Yakutia) M.E. Nikolaev) (Natalia N. Kolodeznikova, Main Advisor, Permanent Office of the Republic of Sakha (Yakutia) to the President of the Russian Federation).

In sociology, there are various discursive practices, approaches to new cultural history, research of collective trauma, which make it possible to see the complexity and ambiguity of experience, to turn the perspective from the total to the particular, returning history to the human dimension in specific spatial-temporal and nationalcultural coordinates.

Within the social theories, the past is viewed through the prism of social interactions, as a phenomenon generated by social reality and influencing it; the philosophical perspective implies the interpretation of the past as an abstract category, an intrinsically valuable phenomenon, studied outside the historical and cultural context; in semiotic studies, the past is perceived as a renewable "archive" of texts that invade the space of the present and form its value-normative appearance; from the standpoint of historical knowledge, the past is interpreted as an object and a result of scientific reconstruction.

In the 2008 study aimed to identify features of life strategies of the second or third generation of forced migrants to the North, the methodological foundation was the Indigenous Methodology; the theory of the "social framework of memory" by M. Halbwachs [2,3]; the theory of cultural trauma by P. Shtompka [4] and the theory of cultural memory by J. and A. Assman [5,6,7].

The research used the methods of questionnaires, indepth interviews, media content analysis, historical and comparative analyzes.

One of the most important questions was "What helped the Churapchins to withstand the years of resettlement?". According to the settlers' descendants, these were strength of mind, vitality $-29,4 \%$, faith that they will return home - $26 \%$, diligence, inexhaustible optimism - $14.5 \%$, mutual assistance - $13,1 \%$, good health $-6.6 \%$, strong family relations $-6.3 \%$, traditional worldview $-2 \%$.

Thus, collective memory remains one of the main sources of historical information for representatives of the Yakut ethnic group, and more modern methods for collecting information remain unclaimed. More than half of the respondents do not use scientific sources when receiving new information about the forced resettlement, which reduces the level of reliability of knowledge about the tragedy outside the family circle and restrains the process of the trauma of grief and loss in the narratives of the collective memory.

The second module "The Arctic as a social phenomenon" examines various approaches to the Arctic 
identity, its features and processes of formation; the results of the 2016-2019 research are presented. "Arctic Identity: Global, National and Local Processes of Construction and Transformation" describes Arctic identity as a continuous, socially structured process based on a sense of the Arctic homeland for both indigenous peoples and settlers (Daria V. Burnasheva, $\mathrm{PhD}$ (Cultural Studies)). It presents the concept of "Arctic" in terms of values of students of the NorthEastern Federal, Murmansk Arctic, and Northern (Arctic) Federal Universities (Daria N. Filippova, postgraduate student); concept, principles and functions of local self-government in the Arctic countries are described (Mikhail A. Pogodaev, Candidate of Economic Sciences, Oksana D. Romanova, Candidate of Sociological Sciences, Anna V. Mikhaylova, Candidate of Economic Sciences, Klavdiya D. Barashkova, Senior Lecturer).

Module 3 "Social dynamics in the Arctic" describes results of the studies on the development of volunteerism in the Republic of Sakha (Yakutia) (Galina G. Alekseeva, Candidate of Sociological Sciences); origins, development factors and a resource potential of Arctic tourism (Evdokiya P. Vinokurova, Candidate of Culturology); socio-cultural aspects of the Arctic sports games are described. The role of the Arctic in the formation of a coach's personality is identified (Vasiliy N. Alekseev, Associate Professor). Destructive social processes in the Arctic are presented Yuriy I. Zhegusov, Candidate of Sociological Sciences.

Sport as a socio-cultural institution has a huge potential; it can influence social problems, preserve and develop society, shape public opinion, create a positive image of the region, and contribute to the socialization of the younger generation. There are studies on the international sports games "Children of Asia" as a sociocultural project that contribute to a healthy lifestyle in the republic; sports facilities performing socio-cultural functions; promotion of ethno and geo-cultural ideas and symbols of Yakutia; ways to strengthen the attractiveness of Yakutia in the Asian world [8].

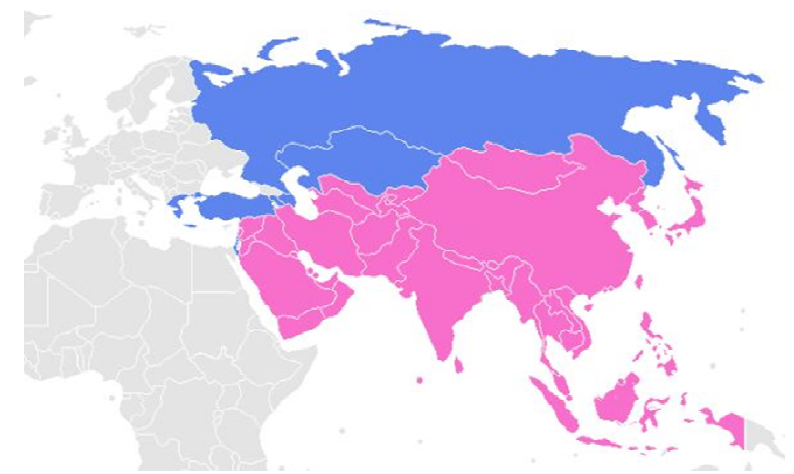

Fig. 1. Map of the geography of the «Children of Asia» (19962016)

The experience of holding international competitions of the countries of the circumpolar region - the Arctic Winter Games-influences the formation of the ethnic, regional and transnational identity of the peoples of the
Arctic. Today, the traditional sports of the peoples of the Arctic attract the attention of the world sports community not only by their originality, but also by special techniques of exercises and training, honed over many centuries, which are of considerable interest to those who are engaged in professional sports. Sports and mass events are designed to introduce the Arctic peoples to each other's cultural traditions. Such a unique event, which harmoniously combines the sports and cultural components, is the Arctic Winter Games. The Arctic Winter Games are the largest sports and cultural event for the youth of the Arctic [9].

National sports in Yakutia were born in the process of life activity of the population of the northern territory in extreme climatic conditions. The formation of distinctive sports was greatly influenced by the natural, geographical, industrial and ethnic characteristics of the peoples inhabiting the vast territory of Yakutia.

The national exercises reflect the struggle for existence in the harsh, extreme conditions of the Far North. Traditions of physical education and spiritual culture should be considered as a harmoniously merged unity and as one of the most important and effective means of physical education of the modern younger generation [10].

High-performance sports go beyond the value consciousness of HomoLudens. The highest achievements of athletes have deep historical and personal prerequisites formed in the fates of their coaches. The life path and spiritual values of the coach are a kind of catalyst for the sports achievements of his students, who learn not only sports lessons, but also lessons of citizenship, spiritual and moral values of the coach. Identification of the role of the Arctic in the formation of the coach's personality (on the example of D. P. Korkin). The connection of the life path of the outstanding freestyle wrestling coach Dmitry Petrovich Korkin with the peculiarities of his coaching work and the achievements of his students [11].

Volunteerism as an object of sociological research is becoming increasingly important in connection with the current demands of the management of social practices of volunteerism. Such activity is connected, on the one hand, with positive events - the need to recruit volunteers for major sports competitions. On the other hand, these are social emergencies, which require the help of not only specialists, but also a large number of volunteers. In the third module, volunteerism is considered as a culture of mutual assistance and reveals the typology of approaches to the study of this phenomenon, regulatory and legal regulation, and the stages of the development of volunteerism in Yakutia.

Volunteering is the most active component of civil society, a practical manifestation of civic consciousness and civic responsibility for solving problems that are not subject to individual efforts. At present, the essential characteristic of its development is mobilization and self-organization of the population. In Russian sociology, volunteering is studied in terms of its economic efficiency and management aspects, which is associated with the need to assess the social usefulness 
of the phenomenon and the need to organize spontaneous activities of citizens [12,13].

Peculiarities of the volunteering in Yakutia must be considered within the socio-cultural, constructivist, and ecological approaches. The constructivist approach is used to study the mechanisms of constructing social problems as the basis for creating new areas for volunteer associations. The sociocultural approach makes it possible to study the role of volunteering as an institution of civil society, its specificity determined by ethnocultural traditions, peculiarities of motivation of volunteers in the context of the value-normative structure of society. The ecological approach can explain peculiarities of the volunteering in the Republic of Sakha (Yakutia) determined by harsh climatic conditions, a low population density and a vast territory [14].

The specificity of the regional aspect of volunteering is due to the peculiarities of worldviews of the inhabitants of the North, sustainable life of peoples living in permafrost and extreme climatic conditions. Volunteering in the regional aspect is seen as a method for preserving and strengthening spiritual and moral values, the continuity of culture, folk traditions.

Module 4 "Social differentiation" deals with the problems of northern cattle breeding (Elvira A. Mikhaylova, post-graduate student); "northern delivery" as an urgent social and professional problem in the Arctic (Maria E. Osipova, post-graduate student), social aspects of the mammoth fauna in the Arctic (Avgusta P. Dyakonova, post-graduate student).

Thus, the textbook reveals various approaches using the Indigenous Methodology in the study of modern society, identifies possibilities of the Indigenous Methodology in the study of modern processes in the Arctic, presents an analysis of the practice of using the Indigenous Methodology in sociological research conducted by sociologists of Yakutia over the past three years.

Using this textbook, students will be able to critically analyze modern social processes, social institutions and structures in the Arctic territories. They will know: social problems in the Arctic as a macro-region and in its circumpolar sectors;

be able to: identify causes, trends, challenges, risks and consequences in the Arctic; identify actors in social processes; formulate research and practical tasks, including in interdisciplinary fields and in geoeducational processes;

possess: the ability to carry out theoretical and applied research of social processes in local and regional territories; develop recommendations for eliminating practical problems in protecting social interests of the peoples of the Arctic, participate in the development of programs for the socio-economic development of local communities and the region.

The structure of the textbook is unified for perceiving key points and using electronic educational platforms. It meets the requirements of the federal state educational standard.

\section{Conclusion}

The book is the beginning of the series "Sociology in the Arctic" and the scientific and educational project of Arctic research which forms the basis of Arctic education. Since the current academic year, the discipline "Social Processes in the Arctic" has been introduced into the curricula of Churapcha State Institute of Physical Culture and Sports, the Arctic State Institute of Culture and Arts and the North-Eastern Federal University named after M.K. Ammosov.

\section{References}

1. U. Vinokurova Sibirica, 17(3), 3-15, (2018).

2. M. Khalbwachs Emergency reserve, 2-3 (40-41), 8-27, (2005).

3. M. Khalbwachs, Social framework of memory. (Moscow: New Publishing House, 2007).

4. P. Shtompka, Sociological research. 1, 6-16, (2001).

5. M.Ossowska, Studia Socjologiczne, 2, 47-51, (1963).

6. A. Assman Long shadow of the past: memorial culture and historical politics. (Moscow: New Literary Review, 2014).

7. J. Assman, Cultural memory. Letter, memory of the past and political identity in the high cultures of antiquity (Moscow: YASK, 2004).

8. U. A. Vinokurova, Yu. I. Zhegusov, A. E. Mestnikova, G. G. Alekseeva, V. N. Alekseev Theory and practice of physical culture 3, 94-96, (2017).

9. D. V. Burnasheva, G. G. Alekseeva, L. P. Neustroeva, International sports games "Children of Asia" - a factor in promoting the ideas of Olympism and training sports reserve: materials of the International Scientific Conference, 7-8 July, Yakutsk: RIO media-holding, pp. 166-168. (2016).

10. E. G. Vinokurov, V. N. Alekseev, Sociophilosophical problems of the development of physical culture and sports: monograph (Moscow: Lap Lambert Academic Publishing, 2017).

11. I. I. Gotovtsev, Scientific and pedagogical activity of D. P. Korkin: textbook. (Yakutsk: Churapchinsky State Institute of Physical Culture and Sports; 2016).

12. M. V. Pevnaya Management of volunteerism: international experience and local practices. (Yekaterinburg, 2015).

13. A.V. Ermilova, I. A. Isakova Bulletin of the Perm National Polytechnic University. Socio-economic sciences. $\quad 4, \quad 48-57, \quad$ (2017) https://doi.org/10.15593/2224-9354/2017.4.4

14. P. A. Kropotkin, Mutual aid as a factor of evolution. (Moscow. Ed.: Self-education, 2007). 